\title{
Apple Builds Great Platforms, Too, Not Just Products
}

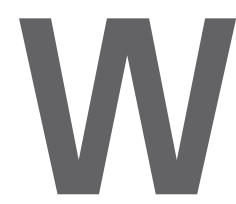

HY IS MICHAEL Cusumano puzzled about Apple? The main point in his Viewpoint column "Technology Strategy and Management" (Sept. 2008) was that you can either build products or you can build platforms. He then claimed that Microsoft is successful because it builds platforms and said he was puzzled by Apple's success since it creates only products that, no matter how great, are still not the basis of a computing platform. Isn't Unix, on which OS X is based, a platform? OS X is the user-interface platform on top of Unix, and Cocoa is the object-oriented development platform.

Cusumano might say they are not industrywide platforms, but that is rather the fault of an industry that fawns too much on incumbent monopolies. Indeed, Apple has done well to survive in such an environment.

The old VHS vs. Beta chestnut is irrelevant. A Google search finds the real reasons for Beta's failure: not technically superior to VHS in all respects and certainly not, for consumers, in the most important one-tape play time. The VHS vs. Beta war involved hardware formats; we deal in software, a much different world.

Cusumano then said that Apple copied its GUI from Xerox and by implication Microsoft then did the same to Apple. However, Xerox rather invited Apple to create such systems. Microsoft took some of Apple's code without Apple's permission, resulting in a legal case that was finally settled in 1997.

The Viewpoint's pull quote hailed that "Despite faster recent growth than Microsoft, Apple relies too much on the fleeting nature of 'hit' products," completely ignoring the design and technical excellence of Apple's products and platforms.

Apple indeed has an excellent platform-OS X, Cocoa, and Unix-that is the basis of Macintosh, the iPhone, and other products. Apple developed its own business model, while $\mathrm{Mi}^{-}$ crosoft relied on the old IBM business model of "Someone else has a good idea, copy it, and crush them." Cusumano ignored this aspect of Microsoft's "success."

Ian Joyner, Sydney, Australia

\section{Author's Response:}

The subject of Apple vs. Microsoft always stimulates emotional and even religiouslike responses from the faithful, sometime impolite diatribes as well. I simply have been looking at what these companies have done for the past $20+$ years and invest no emotion in them or their products. In my interpretation, Apple is primarily a product company and Microsoft primarily a platform company.

Michael Cusumano, Cambridge, MA

\section{Should Manufacturers Fear RFID Tags?}

I see few of the advantages cited by Brian L. Dos Santos and Lars S. Smith in their article "RFID in the Supply Chain: Panacea or Pandora's Box?" (Oct. 2008, Virtual Extension), which claimed that wide deployment of RFID could increase espionage among companies and limit the technology's potential as a competitive edge because they could all read the content stored in one another's RFID tags.

The article further said that new laws might be required to protect the investment companies make in their supply chains. But laws introduced too early that fail to fully consider the interests of all stakeholders, or of society in general, could stifle research, in the same way the U.S. Digital Millennium Copyright Act of 1998 made research in encryption and security more difficult.

Though I agree that rewritable tags that store a product's historical data might pose some risk to user companies, any company's ability to read
RFID tags might also be improved, ultimately representing the killer app of RFID tags.

If consumers were able to check tags and see where, say, a particular item was manufactured, the result could be a more informed choice among RFID-using manufacturers and their products by, say, making it easier to avoid sweatshops or factories that do not comply with environmental regulations; embedded tags that store product histories might also allow for easier recycling or disposal. Rewritable tags could further help consumers check when an item was manufactured, helping them avoid items marketed as the latest and greatest but that actually spent months on a shelf in storage, even as suppliers were counting on consumer ignorance.

Empowerment is great for consumers but would require more honesty from manufacturers and suppliers, so some companies might resist. This is where I would want to see new laws regarding the types of data that could be stored on RFID chips.

Tomasz Rybak, Bialystok, Poland

Communications welcomes your opinion. To submit a Letter to the Editor, please limit your comments to 500 words or less and send to letters@cacm.acm.org.

Coming Next Month in

COMMUNICATIONS

Engineering Rural

Development:Improving

the Performance and

Accountability of Civil Society

Organizations

Computing Challenges

in E-Commerce

WisePad Services for

Sense-Impaired Users

And the latest news about climate change modeling, smartphone functionality, and popular astronomy. 